\title{
- que pensam os professores do ensino fundamental do planejamento didático?
}

\author{
Ademir Rosso ${ }^{1}$
}

\begin{abstract}
RESUMO
O presente trabalho relata uma pesquisa desenvolvida com a colaboração de 12 alunas do Curso de Pedagogia em Séries Iniciais da Universidade do Alto Vale do Itajaí, Campus de Tijucas - SC. O objetivo da pesquisa foi saber o que os professores das Séries Iniciais do Ensino Fundamental pensavam sobre o planejamento didático, a partir de entrevistas semi-estruturadas. A realização da pesquisa deu-se dentro do contexto da disciplina Prática de Ensino em Didática. Do conjunto dos materiais coletados, respeitando-se a diversidade e a heterogeneidade dos dados, pode-se provisoriamente dizer que os educadores, ao mesmo tempo em que se prendem mais aos aspectos didáticos do ensino, manifestam-se favoráveis à necessidade de se planejar as atividades didático-pedagógicas, rejeitando a verticalização do planejamento presente nos sistemas de educação.
\end{abstract}

Palavras-chave: formação de professores, prática de ensino, planejamento didático, didática

\section{Introdução}

O planejamento do ensino tem se apresentado como desvinculado da realidade social, caracterizando-se como uma ação mecânica e burocrática do professor, pouco contribuindo para elevar a qualidade da ação pedagógica desenvolvida no âmbito escolar (Lopes, 1996: 42).

\footnotetext{
${ }^{1}$ Professor da Universidade Estadual de Ponta Grossa / Departamento de Métodos e Técnicas de Ensino. Doutor em Educação.

Olhar de professor, Ponta Grossa, 2 (2):95-109, nov. 1999.
} 
O presente relato apóia-se no material fornecido pelos trabalhos escolares desenvolvidos pelas alunas do Curso Noturno de Pedagogia em Séries Iniciais, da Universidade do Vale do Itajaí (UNIVALI), no Campus de Tijucas, SC. Os trabalhos se desenvolveram dentro da disciplina de Prática de Ensino de Didática, do $8^{\circ} \mathrm{Se}$ mestre do Curso, no semestre 1996/ 1. A disciplina tem a carga horária total de 60 horas/aula, que foram cumpridas mediante um projeto alternativo para as atividades de estágio, conjuntamente com a disciplina de Prática de Ensino em Psicologia.

Como a totalidade das alunas já atuavam como professores e vinham realizando estágios nas Séries Iniciais e como não haviam vivenciado ainda uma prática efetiva de pesquisa, optou-se por investigar um tema que suscita polêmicas e resistências das mais variadas formas entre os professores. A opção mais comum seria a de localizar escolas onde os acadêmicos/estagiários de Pedagogia fizessem algumas observações para a confecção de um Projeto de Estágio e desenvolvessem a docência com a apresentação de um relatório final. Como a regulamentação da Prática de Ensino da UNIVALI permite formas alternativas de estágio, optamos em trabalhar no aprofundamento de um nó cego da Didática, não tão fácil de desatar.

Além de a pesquisa ter como objetivo geral possibilitar as alunas/pesquisadoras subsídios teóricos e práticos visando ao desenvolvimento das atividades de forma desafiadora, tinha por fim colocar as alunas em contato com as concepções que os professores manifestam sobre o planejamento didático e confrontar as concepções com a prática docente.

A tentativa de desatar esse nó passou primeiramente pelo estudo do texto de Candau (1985: 12-22), que possibilitou a compreensão das diferentes concepções da Didática e das razões históricas e ideológicas que perpassam o nó. Partindo do estudo das razões históricas e pela sua prática verticalizante e centralizada, compreendeu-se por que o planejamento nem sempre é uma questão bem vista e está cercada de reticências pelos educadores.

Num segundo momento, o grupo deteve-se em estudar alternativas de pesquisa que pudessem apreender esse contexto. Estudou-se a técnica de coleta de informações por meio de entrevistas, optando-se pela modalidade de entrevista semi-estruturada conforme proposta por Triviños(1990), seguindo-se da realização de uma entrevista piloto. Enquanto as alunas realizavam as entrevistas e faziam a sua transcrição, durante as aulas, passamos a estudar um marco teórico sobre o planejamento didático. Na oportunidade, optou-se pelo texto de Haydt (1994: 94-111). Os professores informantes atuam, na sua grande maioria, no Ensino Fundamental de $1^{\text {a }}$ à $4^{\mathrm{a}}$ Série e pertencem às mais diversas redes de ensino, com formação que varia desde o Ensino Médio (Magistério) à PósGraduação Lato Sensu .

Como as metodologias da Pesqui- 
sa Científica desenvolvidas nas graduações normalmente conseguem chegar até a elaboração de um projeto de pesquisa, sem entretanto resultar numa pesquisa efetiva e no seu relatório, essa última etapa do processo foi a mais desafiante para o grupo. Se durante a realização das disciplinas de Instrumentação de Pesquisa não há um trabalho em conjunto com os demais professores, uma vez cursadas, poucos professores a cobram nos trabalhos realizados pelos acadêmicos. Dado o conjunto das dificuldades de ser um Curso Noturno, de todas as alunas trabalharem no mínimo um turno na escola, de poucas alunas se utilizarem da informática, da realização em paralelo do Estágio nas Séries Iniciais do Ensino Fundamental, da carga horária disponível etc., não se conseguiu avançar na análise das informações coletadas. Por isso, o conjunto de informações presentes na monografia consistiu quase que exclusivamente nas entrevistas no seu estado puro. As análises efetuadas pelas alunas/pesquisadoras ultrapassaram em pouco o nível da constatação.

Os materiais coletados nas atividades das alunas favoreceu o desenvolvimento de uma pesquisa que, nas condições possíveis da disciplina, resultou numa monografia em que se fez o confronto de um marco teórico com as informações coletadas. A análise qualitativa complementar que fazemos tem como objetivo identificar a presença dos elementos teóricos/práticos mais significativos, que denotem entendimento ou distorções sobre o pla- nejamento didático. Em menor extensão, também analisaremos o significado formativo da alternativa adotada para a Prática de Ensino em Didática.

\section{Metotodologia da pesquisa}

A investigação promovida pode ser caracterizada como qualitativa por ter como objetivo primordial a descrição das características do planejamento didático executado no ambiente escolar. O critério para a descrição foi o de captar as situações vivenciadas pelos professores; portanto, não nos limitamos a conhecer a opinião dos professores do Ensino Fundamental de $1^{\mathrm{a}}$ a $4^{\text {a }}$ Série sobre o planejamento. Mais que isso, procuramos obter uma compreensão mais profunda e detalhada possível da visão teórica que possuem. Para captar essa profundidade, usamos os princípios da entrevista semi-estruturada (Trivinõs, 1990).

As entrevistas foram realizadas pelas alunas/pesquisadoras do curso de Pedagogia, após estudarem os seus princípios e realizarem uma entrevista piloto, a qual entrevista piloto foi apresentada e discutida com os demais colegas de curso para avaliar as perguntas feitas e a forma geral de sua condução. Essa discussão era para ver se conseguiam captar a realidade a que nos propúnhamos. A discussão das entrevistas-piloto acabou determinando uma certa convergência das questões feitas pelas alunas/investigadoras. As entrevistas definitivas, com essa iniciativa, acabaram tendendo a 
ser entrevistas estruturadas.

Combinou-se que cada aluna selecionasse três informantes que, de preferência, atuassem no Ensino Fundamental de $1^{\mathrm{a}}$ à $4^{\mathrm{a}}$ Séries. Já que se pretendia avaliar o resultado da formação recebida na Didática de Ensino Médio (Magistério) dos três informantes entrevistados por aluno, determinou-se que se fizesse o possível, dentro ou próximo ao ambiente de trabalho, e que dois deles possuíssem formação no Magistério (Ensino Médio) e um fosse graduado em nível superior. Com isso, pretendia-se avaliar se a formação recebida durante a Graduação contribuía para o aprofundamento da idéia do planejamento didático obtida no Curso do Magistério.

Como as alunas/investigadoras eram de Curso Noturno e trabalhavam na educação, a escolha acabou recaindo em professores que possuíam uma maior proximidade com o local de trabalho ou, bastante próximo desse critério, buscou-se a ocasião favorável ou outro critério qualquer, desde que satisfizesse as condições estipuladas para a formação profissional.

As condições prévias da realização da entrevista levaram muitos dos possíveis candidatos a "agradecerem" o convite, ao saber que suas opiniões seriam gravadas. Os dados foram coletados a partir de entrevistas gravadas em fita cassete, que depois de transcritas e analisadas, foram armazenadas em disquetes.

Antecedendo as entrevistas, foi feito um trabalho de sondagem em diversas escolas, a fim de identificar a cli- entela e pedir permissão para explicar os objetivos do estudo. A partir dessa abordagem inicial, marcou-se o dia e horário para as entrevistas. A coleta de dados foi realizada nos meses de abril e maio, período compreendido entre 17/04 a 08/05 de 1996.

Nas entrevistas, a tentativa era a de levar o informante a se manifestar sempre da forma mais espontânea possível e independente de uma racionalização prévia das suas idéias sobre o planejamento didático. Na maioria dos casos, foram-lhe dirigidas algumas perguntas complementares, procurando situá-lo dentro do contexto mais amplo do planejamento. Em alguns casos, conforme o andamento da entrevista, foram feitas outras questões fora das mais comuns, que possibilitassem ao entrevistado explicar com mais detalhes o seu ponto de vista.

A hipótese de trabalho fundamentou-se no pressuposto de que subjacente à prática educativa, havia uma aversão generalizada ou velada ao planejamento didático. E de que, por conseqüência disso, "sua prática (...) é formalizada, ritualística normalmente cópia de um produto ideal acabado". E a sua realização visa o simples "cumprimento de normas burocráticas” (Brandão, 1985: 57).

A população de informantes é constituída de trinta e seis sujeitos que estão caracterizados individualmente, conforme a tabela 1. Quanto à titulação, ao tempo de magistério e ao grau de ensino onde atua ou atividade educacional, temos os escores expressos na tabela 2 . 
Tabela 1

\begin{tabular}{||ll|ll|ll||}
\hline Inform & Caracterização & Inform & Caracterização & Inform & Caracterização \\
\hline AMC & fl-4; 10am & FGP & fl-4; 3am; Mg & MMD & fl-4; 8am; Mg \\
AML & fl-4; 8am; Pdi & FLG & f5-8; 4am; $\mathrm{L}$ & MPC & fl-4; 15am; Mg \\
AND & fl-4; 7am; Pd & IVN & fl-4; 11am; Mg & MRL & apae; 8am; Mg-ad \\
BLM & fl-4; 2am; M & JAC & f5-8 e M; 12am; L & MSM & OrEd; 25am; Esp \\
BSC & f-14; 9am; Pd & JPF & fl-4; 6am; Pdi & PSN & OrEd; 10m; Esp \\
CCF & fl-4; 6am; Mg & JPW & fl-4; 6am; Pdi & RMA & fl-4; 6am; Pd \\
CGS & f5-8,M; 6am; Eng & KKS & Mg-M; 3am; Mg & ROM & fl-4; 5am; Pd \\
CLD & fl-4; 4am; Pd & LMC & fl-4; 13am; Esp & ROS & apae; 4am; Mg \\
CMS & fl-4; 4am; Pd & LTR & fl-4; 10am; Mg & SMC & fl-4; 10am; Pd \\
CSP & OrEd; 11am; Esp & MAA & fl-4; 15am; Mg & SMF & fl-4; 14am \\
DVL & fl-4; 10am; Mg & MDM & fl-4; 3,5am & VLR & fl-4; 10am; Mg \\
EFW & fl-4; 4am; Pd & MJG & f-14; 15am; Mg & VVR & fl-4; 2am; Mg \\
\hline
\end{tabular}

Legendas:

Inform = informante identificado por uma sigla de três letras maiúscula $(\mathbf{X X X})$.

O local de atuação no sistema de ensino está assim representada: f1-4= Ensino Fundamental de $1^{\mathrm{a}}$ à $4^{\mathrm{a}}$ Série; f5-8= Ensino Fundamental de $5^{\mathrm{a}}$ à $8^{\mathrm{a}}$ Série; OeEd= Orientação Educacional; e Apae.

A caracterização do tempo no magistério é dada por (am);

O grau da formação profissional, está assim representado: Mg= Magistério e Mg-ad= Magistério com Estudos Adicionais; $\mathbf{P d}=$ Pedagogia; $\mathbf{P d i}=$ Curso de Pedagogia em andamento; $\mathbf{L}=$ Licenciatura; Esp= Curso de Especialização e Eng= Engenharia.

Tabela 2

\begin{tabular}{||rr|lr|lr||}
\hline \hline Titulação & & Atividade & \multicolumn{2}{|l||}{ Tempo de magistério } \\
\hline Especialização & 5 & Apae & 2 & até 5 anos & 11 \\
Pedagogia & 8 & Ens. Fund. 1 à $4^{\mathrm{a}}$ & 26 & de 6 a 10 anos & 16 \\
Pedagogia & 3 & Ens. Fund. 5a à $8^{\mathrm{a}}$ & 4 & mais de 10 anos & 9 \\
(incompleto) & & & & & \\
Licenciatura & 2 & Ens. Médio - Mag. & 1 & & \\
Engenharia & 1 & Orient. Educ. & 3 & & \\
Magistério & 15 & & & & \\
Não declararam & 2 & & & & \\
\hline \hline
\end{tabular}


As entrevistas gravadas e transcritas passaram primeiramente por um processo de estudo para determinar as categorias de análise e a apresentação das entrevistas deu-se por informante. Para se proceder a uma análise de caráter transversal, foram rearranjadas e reagrupadas em função das perguntas que contêm as categorias temáticas. Apesar dessa estratégia possibilitar um melhor mapeamento e paralelismo das idéias, prejudicou a categorização e o traçado do perfil teórico mais amplo dos informantes. A heterogeneidade das informações coletadas por entrevistas semiestruturadas dificultou a tabulação de respostas dentro de parâmetros quantitativos que pudessem dar uma amostragem da extensão das idéias. As informações aqui expostas serão acompanhadas do autor da informação, que será identificado por uma sigla de três letras maiúsculas (XXX).

Dadas as limitações de espaço para o relato, retiramos as contribuições das alunas invetigadoras sobre a importância da experiência para a sua formação.

\section{As Informações Coletadas}

Não se é educador como se é operário de uma fábrica (...). Não há como ser educador na hora em que bate o ponto e deixar de sê-lo na hora em que o relógio indica o fim do expediente (DVL).

A análise das informações coletadas compreende as seguintes cate- gorias relativas ao planejamento didático: as relações espaço-temporais de sua elaboração, a relação entre planejamento e qualidade de ensino, a importância do planejamento, as reinvindicações feitas aos seus coordenadores, o planejamento com o contexto mais amplo da educação, a relação do planejamento com a avaliação escolar, o planejamento e os conteúdos escolares, planejamento e atitude crítica. Retiramos dessa versão a percepção das alunas investigadoras sobre o trabalho de pesquisa e seu valor formativo.

A primeira categoria que podemos levantar das informações coletadas é a espaço-temporal. Sobre ela, as alunas entrevistadoras perguntaram aos professores quanto tempo dedicavam ao planejamento didático. As opiniões foram muito variáveis e vão de alguns minutos até o dobro de tempo que se permanece em sala de aula. Outros informantes declararam que o planejamento também está em função dos conteúdos a serem trabalhados e da confecção do material didático. É importante notar que para os informantes o planejamento didático não se restringe à elaboração dos planos, mas inclui também a preparação da aula e a confecção de materiais didáticos.

Já que esta é uma das atividades docentes que normalmente não estão inclusas nos contratos de trabalhos, surgem alternativas como o aproveitamento das folgas que ocorrem durante as aulas de Educação Física, Educação Artística ou demais disci- 
plinas que são trabalhadas por outros professores. Uma outra alternativa são as reuniões semanais ou mensais em que se suspendem as aulas e a escola dedica um dia para planejar suas atividades. Uns professores planejam diariamente o seu trabalho, outros o fazem no final de semana.

O espaço onde o planejamento é elaborado normalmente é o doméstico. $\mathrm{Na}$ escola, se restringe mais às reuniões programadas ou dentro dos intervalos em que os seus alunos estão tendo aulas com outros professores. Com essas alternativas, muitas vezes com a conivência do corpo diretivo da escola, se consegue dar um jeito nas limitações impostas pelas condições objetivas de trabalho.

Uma segunda categoria pode advir das perguntas sobre a relação existente entre o planejamento e a qualidade de ensino. Encontramos respostas que vão da simples confirmação sem justificativa, passando pelas desculpas relativas à verticalização do planejamento em algumas instâncias, ou reduzindo o seu espectro aos conteúdos escolares. É o que afirma RMA: para quem tem opção de escolher o conteúdo de acordo com sua realidade, acho que sim. No nosso caso, apenas repassamos conhecimentos. Para FGP, pelo planejamento de uma aula antes de executá-la, temos mais condições de criar novas técnicas e meios de facilitar o aprendizado.

Por vezes o planejamento é concebido como rigidez e imposição, sendo, portanto, incompatível com a criatividade e a capacitação do bom professor. É o que diz MRL: não que sem este planejamento um bom professor, que usa a sua criatividade, não consiga melhorar o ensino. Ser um bom professor pode ser merecedor de certas ressalvas.

Algumas respostas não discutem diretamente uma possível relação entre planejamento e qualidade de ensino e atribuem a baixa qualidade do ensino às próprias crianças, como a de LMC, que afirma: o que vem ocorrendo é o desinteresse total das crianças. Está dificil de passar uma mensagem, eles não têm interesse em pegar um conteúdo.(...) não vejo interesse nas crianças em aprender nada, só querem brincar. Ou a de ROS, que atribui essa baixa qualidade a vários fatores e (...) os mais importantes alguns são a miséria e a falta de um planejamento familiar do Estado para auxiliar as famílias.(...) Numa família carente, onde tem dez filhos, geralmente os filhos maiores começam a trabalhar muito cedo, (...) para tentar ajudar na renda familiar. Apesar de reconhecerem a origem sócio-econômica do problema, esses professores não vislumbram uma possibilidade para a ação escolar.

Outros professores, dentro de um referencial crítico, compreendem que a qualidade de ensino, embora dependente de um bom planejamento, se apóia também em outros fatores, como, por exemplo, as condições de trabalho na escola. IVN acredita que melhoraria se o professor tivesse mais 
tempo ou que não se reduzisse, de acordo com AML, ao simples preenchimento de formulários para controle.

As respostas relativas a questões que solicitavam uma relação entre a qualidade do ensino e a necessidade do planejamento podem ser cruzadas com a pergunta Quais seriam as conseqüências de se abandonar todo $e$ qualquer tipo de planejamento na Escola?, a qual mantém implícita a necessidade do planejamento. Consideramos importante a análise das respostas dadas a essa pergunta, por se constituir numa dupla negação. Das respostas, listaremos principalmente as razões relativas a sua finalidade.

Mas, tomando inicialmente as respostas pelo lado da ausência do planejamento, defende-se, como JPF, que o planejamento ainda é um ponto de apoio para os professores. Segundo VLR, implicaria um maior despreparo do professor. Para EFW, com o abandono do planejamento (a situação) (...) tende a piorar, trazendo conseqüencias como: desinteresse. Para LMC, traria acomodação. E para $\mathrm{KKS}$, os professores fariam coisas que não têm nada a ver com as que os alunos precisam.

Segundo alguns sujeitos, as razões principais que levam os professores a querer abandonar o planejamento é, conforme afirma ROM, a falta de participação, por não saber conduzi-lo, falta de tempo e a não remuneração. Dentro de uma compreensão mais crítica, se expressa MPC: solução não é abandonar o planejamento de ensino, mais sim colocar em prática o que desejamos alcançar. Segundo LMC, ao se referir aos planos provenientes das secretarias de educação, se o professor não está interessado naquele plano (...) deve procurar outra alternativa.

Para nossa surpresa, a pessoa que menos estudou as grandes questões educativas e, por isso, é alvo de ataque de outros informantes, CGS, afirma que o planejamento é de fundamental importância porque é da formação do ser humano que estamos tratando. Seu pensamento é completado e mais detalhado pela contribuição de AND. Segundo ela, sem o planejamento corre-se o risco da criança não ter o rendimento necessário para o desenvolvimento intelectual, afetivo e cognitivo e social. A importância do planejamento como guia das intenções para o desenvolvimento do compromisso educativo é defendida pela pergunta de CLD: Como ajudar o aluno a construir o saber se ele vivesse num ambiente desorganizado, onde os professores teriam que adivinhar seus anseios e se responsabilizarem sozinhos pelo ensino, sem a participação da escola e da comunidade?

Entre o conjunto das respostas, encontramos duas que discordam. A primeira delas defende a autonomia irrestrita do professor para determinar o que ensinar aos seus alunos. É o que declara JAC: Se a escola tiver profissionais qualificados, acredito não haver grandes conseqüencias para os alunos, já que o planejamen- 
to deve estar na cabeça do professor. Este é que tem o direito de saber o que ensinar, e não o que foi planejado no papel. A segunda delas defende o livro didático. Vejamos a declaração de LMC, sem desviar a atenção do seu grau de titulação: Aquela coisa de ter que ficar fazendo o plano, acho desnecessário. Tu tem livro, tem outra forma de fazer, não precisa estar com objetivo, com a avaliação, com a atividade etc.

Ao responderem a pergunta se você fosse o Supervisor Escolar ou Coordenador Pedagógico, como você coordenaria o planejamento? tornam-se importantes as sugestões dos informantes, ao se colocarem no papel de responsáveis pelo planejamento, por representarem os principais anseios, críticas de práticas conhecidas que, de certa forma, vêm contribuindo para um melhor planejamento. Apesar de algumas respostas requererem uma explicitação adicional, as sugestões apresentadas podem esconder queixas a respeito da forma como o planejamento é realizado nas escolas. Tais reclames podem estar baseados no fato de os supervisores e coordenadores terem sido, no passado, os principais agentes do planejamento com conotações tecnicistas e serem, em última análise, as pessoas que cobram o planejamento dos professores.

Importante notar-se a preocupação em estabelecer laços com a comunidade. Essas iniciativas passariam por levantamentos de campo para dar respostas concretas aos problemas da comunidade. Das vinte e duas respostas dadas à pergunta, pelo menos um quarto delas se refere a essa necessidade. É o que diz ROM: uma pesquisa de campo, com dados sócio-econômico-cultural para conhecer a realidade da clientela; (...) elaboração de um planejamento flexível contando com a participação da comunidade e da escola e procurando trabalhar conteúdos compatíveis com a realidade escola/comunidade. Após o estabelecimento do contato com a comunidade e antecedendo o planejamento propriamente dito, BSC propõe uma sondagem dos alunos.

Deixando de lado essa visão mais macro, do sistema escolar como um todo, outros estão mais interessados em elementos do dia-a-dia da Escola e o contato direto com os professores. Expressam que: procurariam trabalhar o máximo possível junto ao professor tanto no planejamento como no seu acompanhamento (FLG), observariam e ajudariam no planejamento semanal, tirando as dúvidas e discutindo as experiências dos educadores (ROS). Já KKS, pelo menos uma vez por mês, faria uma reunião, para que os professores partilhassem experiências de sala de aula. Afinal, sozinha a gente, às vezes, não sabe o que fazer.

Entre as questões propostas, que buscavam o entendimento do planejamento no seu contexto mais amploa educação -, foram feitas algumas perguntas que solicitavam o conceito de educação ou a sua relação com o 
ensino. Foram obtidas dezessete respostas. Dessas, cinco respostas não foram aproveitadas por não terem os entrevistados entendido direito a questão ou por serem respostas evasivas.

Dentre as respostas, encontramos alguns elementos que se referem à sua natureza formativa, como AML, que afirma ser o processo de desenvolvimento da personalidade, envolvendo a formação de qualidades humanas (...) tendo em vista a orientação da atividade humana na sua relação com o meio social, num determinado contexto de relações sociais. A mesma idéia é expressa com outras palavras por FGP: é o aperfeiçoamento da pessoa em todos os aspectos: afetivo, cognitivo e motor. Ao se referirem ao seu aspecto formativo, encontramos outras caracterizações do processo como de duração vitalícia, onde o ser humano aprende coisas a cada instante, e também, é influenciado pelo meio onde vive (FLG), em que professor não é o único agente e que a escola só conseguirá preencher sua função quando houver o entrosa-mento dos pais com a escola e desta com a comunidade (LTR).

Se quatro professores se referem mais aos seus aspectos de natureza intrínseca, sem nomear para que a educação, outros professores resgatam com suas falas a natureza política da mesma. Educação é um ato ou processo político que está fundamentado numa concepção de mundo, de conhecimento, de homem e de sociedade (MSM). Noutras palavras, é indispensável para uma mudança social (CSP), tendo uma visão crítica do mundo em que vive, conduzindo-o a perceber que está integrado em uma sociedade e que poderá transformá-la (MJG). Há também educadores como JAC que, dentro da teoria reprodutivista, acreditam que quanto mais se investe em educação, mais culta e promissora é a sociedade. E, como no Brasil, investir em educação não é a principal meta, estamos mais dependentes e subdesenvolvidos.

Apesar de não ter sido objeto de pergunta nas entrevistas, poucos entrevistados manifestam espontaneamente a relação entre planejamento e avaliação escolar. Fizemos um rastreamento de procura da palavra na versão eletrônica e encontramos nove passagens que mencionam a palavra avaliação. Procuramos, então, as palavras "prova", "teste" e "exame", que poderiam contextualizá-la melhor, mas não encontramos menção alguma. O ausência ou silêncio do tema nas falas dos professores não implica, na mesma proporção, falta de visão; indica, sim, que não foi devidamente explorada pelas entrevistadoras. A avaliação, nas vezes em que foi citada, pode expressar três idéias: como um elemento integrante do plano de ensino, como avaliação do plano de ensino e como avaliação da aprendizagem do aluno.

Quanto à avaliação do ensino e do planejamento, para AND, é no horário vespertino que faço a avaliação dos conteúdos trabalhados no período 
matutino. No caso de SMF, no final de cada aula, para verificar se o que foi proposto foi alcançado. Já MJG, olhando para a aprendizagem do aluno e a sua dimensão política, diz que avalia os trabalhos que são feitos em sala de aula, a participação. Enfim, avalio tantas coisas, que na realidade o meu objetivo não é apenas fazer com que o aluno saiba forçadamente a ler e escrever, mas é o de levá-lo a ser crítico ecooperativo.

Considerando as categorias de objetivos identificados pelas pesquisadoras (Reznik \& Ayres, 1995: 105115) sobre o que se encontra na literatura didática, identificamos a visão clássica, na qual a sua formulação é encarada de forma estritamente pedagógica, enfatizando o "como" formular objetivos precisos e sua importância, sem uma discussão de para que e para quem se ensina. Vejamos alguns exemplos. BLM afirma que faz o seu plano semanal (...) com objetivos que se referem ao comportamento dos alunos e não do professor e que estimule o interesse e para facilitar a compreensão e a participação do aluno. Já para LTR, os objetivos são (...) a descrição clara do que se pretende alcançar como resultado da nossa atividade. Mais um exemplo, onde a diversidade dos elementos apresentados concorrem para reforçar o paradigma tecnicista. VLR procura, com o planejamento, definir(...) as metas a serem atingidas (objetivos), o tempo aproximado necessário para que estas metas sejam concretizadas, as pos- siveis formas para alcançá-las e como constatar se de fato se concretizou a aprendizagem por parte dos alunos. Dentro dessa visão, a educação é entendida como o desenvolvimento da personalidade e ajustamento aos meios físico, social e cultural. Não há, pois, muita preocupação com os fins da educação.

Diante dessa visão levanta-se uma série de críticas, situando a formulação dos objetivos dentro de uma concepção mais geral do processo ensino-aprendizagem, que, apesar de buscar uma maior relação com os objetivos mais gerais da educação e com os contextos sócio-culturais, permanece dentro dos limites pedagógicos. MJG faz uma crítica afirmando que $o$ planejamento, para muitos professores, não funciona por não ter objetivo na vida, muitos menos no campo profissional. Talvez não tenham se encontrado na educação e não compreenderam que precisa ser valorizado. Vejamos outra manifestação de CLD, dentro da mesma concepção: Meu planejamento é voltado para o aluno. Nem sempre sigo o que é determinado pela proposta curricular; pois planejamento não é um documento pronto e acabado; é um processo contínuo que exige mudanças. Meu planejamento define uma linha de ação proposta pela escola e pela necessidade da comunidade.

A análise da forma como são concebidos os conteúdos no conjunto do planejamento só foi possível a partir de informações indiretas sobre o as- 
sunto. Mas, mesmo assim, possibilitanos vislumbrar que, apesar de ser uma categoria predominante nas ações pedagógicas, não o é, na mesma proporção, em termos da sua reflexão.

De maneira geral, parece haver uma tendência de buscar uma correspondência entre os objetivos e os conteúdos, sua relevância para o grupo social, acessibilidade e solidez. Porém, nada é mencionado quanto ao caráter científico e sistemático dos conhecimentos. Talvez se deva ao fato de os professores, em sua maioria, atuarem no Ensino Fundamental de $1^{\text {a }}$ à $4^{\mathrm{a}}$ série. Vamos ver algumas declarações dos informantes. CLD afirma que existem conteúdos chatos, que não condizem com a realidade do aluno. Já para RMA, é necessário adequar os conteúdos mais dentro da realidade da nossa clientela. Como diz AND, o professor deve fazer o plano de aula diariamente para melhor programar os conteúdos dentro das necessidades de cada turma.

Há o reconhecimento de DVL da necessidade de se programar atividades para conhecer os alunos, o nivel de aprendizagem, a situação de cada criança pelo contato com a família. Essas iniciativas facilitam o planejamento. Junto com as estratégias de interpretação do contexto e das condições cognitivas das crianças é indispensável que o professor tenha um bom critério de seleção dos conteúdos e a escolha seja feita em torno de conteúdos mais importantes, mais centrais e mais atuais, como assevera LTR.
Entre as informações, encontramos de diferentes formas a preocupação dos conteúdos com o seu aspecto predominantemente pedagógico, chegando ao extremo de parecer que a preocupação maior é o conteúdo pelo conteúdo. Como afirma CLD: analiso os conteúdos, geralmente procuro auxilio nos livros e isso leva muito tempo.

Como a dinâmica do planejamento implica uma atitude permanentemente dialética entre o contexto social e o escolar, entre as necessidades dos educandos e a cultura estabelecida, entre ensino e aprendizagem, procuramos pela sua menção direta no texto das entrevistas, mas não encontramos nenhuma menção da palavra. O mesmo aconteceu ao procurarmos as palavras "oposição", "conflito" e "confronto", que podem ser associadas à dialética. Procuramos então "processo" e "dinâmica", ligadas ao ato de planejar, por serem palavras que expressam movimento. Encontramos três vezes a palavra processo e não encontramos nenhuma vez a palavra dinâmica.

\section{Considerações finais}

A Prática de Ensino, como uma disciplina teórico-prática, concebida como um processo de preparação, de leitura, de inserção e teorização da realidade escolar para os futuros professores, dentre suas múltiplas atribuições implícitas, de forma alguma de- 
veria se restringir a um determinado número de horas de docência para a obtenção dos créditos finais do curso. Para que sejam possíveis seus objetivos, deve haver um confronto permanente dos marcos teóricos com o contexto escolar. Os trabalhos de natureza alternativa, como o da experiência relatada, são válidos para o desenvolvimento de todas as disciplinas que contribuem para a formação docente, não somente para a Prática de Ensino em Didática. O projeto alternativo representou um avanço em relação à forma convencional de Estágio Supervisionado e a introdução da metodologia investigativa se constitui num elemento a ser incorporado na Prática de Ensino.

As informações apresentadas ante a nossa hipótese inicial de trabalho de que subjacente à prática educativa havia uma aversão generalizada ou velada ao planejamento didático-, evidenciam das mais diversas formas que: os informantes manifestam resistências que são maiores fora do círculo dos formados nos Cursos de Magistério e da Pedagogia; há uma tendência crescente de relativização do planejamento didático à medida que os professores atingem graus maiores de formação. Para os professores que fizeram essa caminhada, o planejamento parece cumprir o papel de um dos elementos necessários ao bom desempenho docente, porém nunca é considerado como o determinante do desempenho.

Apesar do espaço para a confec- ção do plano ser o doméstico, na escola ele ocupa o espaço das reuniões programadas ou dos períodos vagos em que os alunos estão tendo aulas com outros professores. Como as atividades de planejamento normalmente não estão inclusas nos contratos de trabalhos ou planos de carreiras dos professores, no Ensino Fundamental estão se institucionalizando alternativas através das quais, muitas vezes, com a conivência do corpo diretivo da escola, se consegue dar um jeito nas limitações impostas. As alternativas são as reuniões semanais ou mensais, em que se suspendem as aulas e a escola dedica um dia para planejar suas atividades. Por vezes, são mencionadas alternativas institucionalizadas que funcionam mais dentro do paradigma tecnicista e como um mecanismo de controle e centralização do planejamento, do que de uma reflexão sistemática da prática educativa.

A formação inicial em Didática recebida pelos professores, tanto na graduação como no Magistério, não tem a garantia suficiente de favorecer uma boa compreensão do papel do planejamento escolar e da própria educação. As falas dos informantes manifestam que o planejamento didático não se constitui num elemento inerente ao próprio ato pedagógico, sendo freqüente o entendimento de que o ato de planejar é um recurso, uma técnica, de que se lança mão para determinado fim. Por conseqüência, defende-se a idéia de que os profes- 
sores que não se saem bem na escola é por não usarem desse recurso capaz de garantir o sucesso ou por não planejarem corretamente. Essa compreensão do planejamento mantém ainda latente a concepção tecnicista da divisão do ato pedagógico em planejamento e execução, entre os especialistas em planejar e os professores, seus executores. Essa tendência fica mais acentuada ainda se for analisado o planejamento da escola, onde sobressaem os supervisores, orientadores e direção, que chamam os professores para colaborarem e darem sugestões.

As investigações no campo da Didática, no que se refere ao planejamento didático, apesar de haver, nas duas últimas décadas, toda uma produção crítica e alternativa à visão clássica e tecnicista (Libâneo, 1994; Lopes, 1996;), parecem manifestar uma cisão entre os fundamentos teóricos e os aspectos operacionais do planejamento. Como as informações coletadas e trabalhadas não sustentam essa afirmação, levantamos a hipótese de que, para se contextualizar a Didática e a Educação, usa-se de um referencial crítico. Mas, para discutir e orientar os aspectos operacionais do planejamento, se recorre, em muitas situações, a um referencial clássico. Apoiados em Martins (1998: 19), pode-se formular a hipótese de que a organização do trabalho pedagógico na escola se desenvolve dentro de uma organização social individualista, hierarqui- zada e competitiva.

Pelas declarações dos informantes, o planejamento não estaria somente em função dos conteúdos a serem trabalhados e da confecção do material didático, mas incluiria também a preparação da aula e a confecção de materiais didáticos. Em alguns casos, são indicados um processo de leitura da realidade e de tomada de decisões para "se integrar dialeticamente ao concreto do educando, buscando transformá-lo" (Lopes, 1996: 43).

Os informantes revelam o predomínio de uma vivência e de uma representação da experiência pedagógica dentro do relacionamento pessoal e afetivo ou do âmbito estritamente pedagógico, sem atender ou relegando a um segundo plano os elementos de natureza social e política. Essa mentalidade parece estender-se aos conteúdos de ensino, vistos sob à ótica predominantemente pedagógica; enfatizam-se os aspectos lógicos e a acessibilidade dos conteúdos. Pouco é comentado sobre o caráter científico, sistemático, social e político dos conhecimentos.

Nas falas dos professores informantes predominam os elementos de natureza normativa e descritiva do planejamento, em detrimento dos elementos de natureza dinâmica, processual. Entender o planejamento didático-pedagógico dentro de uma perspectiva multidimensional, dialeticamente processado e articulado, é um desafio que se põe à formação docente, seja ela 
inicial ou continuada.

As alunas de Metodologia e Prática de Ensino aprenderam tanto com o planejamento, a coleta de informações, análises e estudos quanto com o contato com os sujeitos informantes da pesquisa. Conseguiram perceber, aproximar e articular os elementos teóricos com a prática, refletindo sobre a realidade escolar no seu todo. Avaliaram e se pronunciaram diante das maiores distorções manifestadas pelos informantes. Sendo assim, o projeto alternativo à Prática de Ensino em Didática cumpriu a função de ser um instrumento de formação docente.

Os depoimentos das alunas destacam a positividade do encontro mantido com outros professores. Elas expressaram admiração pelas práticas e testemunhos, reconhecendo em muitos deles o compromisso e a competência pedagógica. Esse contato tem um potencial formativo elevado, mesmo entre colegas de trabalhos ou próximos ao ambiente de trabalho, que nem sempre tiveram oportunidade de discutir outros assuntos que não os de natureza imediata do dia a dia escolar.

Por parte das formandas, em muitos momentos anteriores à realização da pesquisa, quando se estabeleciam paralelos com o contexto escolar, as opiniões a respeito do professores eram bastante taxativas e causticantes. Chegava-se a afirmar que: as coisas não são melhores porque os professores não querem ou são acomodados. Esse tipo de encontro é valioso pela possibilidade dos formandos se colocarem nas condições objetivas dos colegas e de se reduzir a onipotência reflexiva, passando a discutir suas opiniões.

\section{REFERÊNCIAS BIBLIOGRÁFICAS}

1 BRANDÃO, Z. Abordagens alternativas para o Ensino de didática. In: CANDAU, Vera Maria (org.). A didática em questão. Petrópolis: Vozes. 3. ed. 1983.

2 CANDAU, Vera Maria (org.). A didática em questão. Petrópolis: Vozes. 3. ed. 1983.

3 CANDAU, Vera. Rumo a uma nova didática. Petrópolis: Vozes. 1995.

4 HAIDT, Regina Célia Cazaux. Curso de didática geral. São Paulo: Ática. 1994.

5 KUENZER, Acácia Zeneide e outros. Planejamento e educação no Brasil. São Paulo: Cortez.

6 LIBÂNEO, J. C. Didática. $14^{\mathrm{a}}$ reimpressão. São Paulo: Cortez, 1994.

7 LOPES, A. O. Planejamento do ensino numa perspectiva crítica. In: VEIGA, I. P. A. (Coord.) Repensando a didática. $12^{\mathrm{a}} \mathrm{ed}$. Campinas: Papirus, 1996, p.41-52.

8 MARTINS, P. L. O. A didática e as contradições da prática. Campinas: Papirus, 1998. 